\title{
Full-Scale Testing of Precast Concrete Bridge Using Internal Connector in Negative Moment Region
}

\author{
Heeyoung Lee $\mathbb{D}^{1,2}$ Junki Min, ${ }^{3}$ and Wonseok Chung $\mathbb{D}^{4}$ \\ ${ }^{1}$ Post-doctoral Research Associate, Kyung Hee University, Yongin-Si, Republic of Korea \\ ${ }^{2}$ Post-doctoral Research Associate, University of California, San Diego, USA \\ ${ }^{3}$ Graduate Student, Kyung Hee University, Yongin-Si, Republic of Korea \\ ${ }^{4}$ Professor, Department of Civil Engineering, College of Engineering, Kyung Hee University, 1732 Deokyoung-Daero, Giheung-Gu, \\ Yongin-Si, Gyeonggi-Do 17104, Republic of Korea
}

Correspondence should be addressed to Wonseok Chung; wschung@khu.ac.kr

Received 19 March 2019; Revised 31 May 2019; Accepted 10 July 2019; Published 4 August 2019

Academic Editor: M. Shahria Alam

Copyright (C) 2019 Heeyoung Lee et al. This is an open access article distributed under the Creative Commons Attribution License, which permits unrestricted use, distribution, and reproduction in any medium, provided the original work is properly cited.

Conventional concrete marine structures are difficult to construct on site and can cause pollution of the environment. Therefore, concrete marine structures require the development of methods that can minimize the amount of construction that needs to be performed in the field. This study aims at facilitating assembly through the use of precast girders and precast bent cap and at improving construction efficiency by minimizing cast-in-place structures. The proposed bridge can reduce the negative moment of the girder through continuous connection. In this study, a full-scale connection specimen with a $10.0 \mathrm{~m}$ span was fabricated, and the behavior of the precast connection was evaluated by performing a negative moment performance test. In addition, a finite element model was developed to compare each loading step with the test results. The failure mode of the specimen was that the reinforcing bars yielded at the joint of the cast-in-place section and the precast girder. As a result of the study, this proposed bridge is easy to construct because it minimizes the process of connecting the coping and girders using the internal connector. Also, the proposed bridge has $155 \%$ higher structural performance than the designed load at the negative moment connection part.

\section{Introduction}

Existing marine structures have faced problems such as deck damage and steel corrosion. Such problems decrease durability and structural stability and require cyclic maintenance of the structures. Given that cast-in-place concrete structures require the use of temporary facilities, this may cause difficulties in construction and damage to the marine environment. Precast concrete structures require connection of separate brackets to secure the composite performance at the joints between steel pipes and precast bent caps. As such, it is essential to improve techniques for the construction of bridges that are suitable for the marine environment and can reduce cost and construction period by minimizing on-site construction.

Many studies have been performed on marine structures [1-10]. Soares et al. [11] modeled the effects of relative humidity, chloride, and temperature on the corrosion behavior of steel structures exposed to the marine atmosphere. This study proposed a precise equation for prediction of pollution in marine conditions, and the proposed model provided more accurate predictions of corrosion behavior than existing models by adding constraints from experimental results. Zhang et al. [12] published a study on the corrosion resistance and bonding of geopolymers with hardened cement. The study documented the microstructure and pore structure of geopolymers using a number of analytical techniques. It verified that the microstructure of geopolymers contributed to the resistance to seawater diffusion and bonding with cement, making geopolymers a potential coating material for marine concrete structures. Garcia-Espinel et al. [13] investigated a marine bridge under the seawater. This study investigated the effect of seawater environment on the mechanical characteristics of various 
factors. This study determined the safety factor used in the structural calculation design of marine applications. Bradner et al. [14] tested a series of 1:5 scale reinforced concrete bridge upper structures to determine the effect of wave force on coastal highway bridges. The test system set the stiffness of the horizontal support system to characterize dynamic behaviors and presented data that show the close link between the wave height and load.

Precast concrete structures can upgrade construction performance in the field, but it is necessary to confirm their structural performance. Numerous studies on precast concrete structures have been performed to date through experimental testing and FE analysis. Caner and Zia examined an experimental structural study on link slabs using a full-scale specimen [15]. A two-span full-scale steel-concrete composite bridge was fabricated. The behavioral characteristics of bridges were investigated at diverse boundary conditions. de la Fuente et al. [16] studied an optimized cross section using a numerical model for each precast concrete bridge construction order. Baskar et al. [17] conducted a nonlinear analysis of data from fracture tests of steel and concrete composite plate girders to determine the expected structural behavior of composite plate girders under ultimate loads. Issa and Abdalla [18] studied epoxyjointed single keys in precast concrete structures. Several specimens were fabricated to verify the shear performance and evaluate the effect of temperature on the shear strength of epoxy. The experimental results demonstrated that the failure mode of the specimen was a concrete fracture due to shear force. It was confirmed that the shear strength of the epoxy specimen improved at higher temperatures. Lee et al. [19] examined the composite behavior of an inverted T-bent cap-girder integral steel bridge through a nonlinear FE analysis. This study confirmed the validity of the proposed bridge by predicting its overall composite behavior and comparing the results with those of a test with a full-scale model. Ko et al. [20] studied the composite behavior of the new bent cap joint to ensure proper structural performance. In this study, the connecting steel girders and bent caps were subjected to a two-million-cycle fatigue test. Marí and Valdés [21] studied a continuous bridge constructed of precast concrete beams with $U$-shaped cross section using a $1: 2$ scale model to determine its behavior under permanent load. This study analyzed deflection and strain for 500 days and compared them with the results of a nonlinear and timedependent analysis of prestressed and reinforced concrete structures. Shah et al. [22] tested irregular bolted connections between flanges for continuous precast bulb-T girders. The factors influencing the failure mode of the model and the load capacity of the connection were analyzed.

This study proposes an internal connector that facilitates the connection of steel pier and precast concrete bent caps. The proposed bridge can be constructed with minimum equipment and does not require separate bracket installation. In this study, a full-scale bridge composed of precast girders and precast bent caps including internal connectors is fabricated, and the composite behavior of the connection is studied. A full-scale specimen of the connection between a precast bent cap combined with a steel pier and a precast girder was fabricated. A loading test was also performed so that negative moment could be created at the connection of the full-scale specimen and the behavior of the connection at each loading step was analyzed. The loading test of the connection was conducted based on the design load considering the marine characteristics [23, 24]. In the test, the crack pattern and final failure mode of the test bridge were investigated. Furthermore, the behavior of reinforcing bars and concrete at the key locations of the test unit was examined to confirm their composite behavior. This study develops a three-dimensional (3D) finite element model and verifies its validity by comparing the behavior in each loading step with the test results.

\section{Proposed Precast Bridge}

Cast-in-place concrete bent caps for marine structures may cause environmental problem and require temporary equipment and facilities for the formwork system. Since the proposed bridge is made of precast girder and bent cap, uniform strength can be obtained. Additionally, precast concrete bent caps involve difficult construction techniques in which separate external brackets must be installed for connection with steel piles. In this study, precast girders and precast bent caps with internal connectors, which are suitable for the marine environment, are proposed to improve joint performance and construction efficiency.

Figure 1 illustrates the proposed bridge. This proposed connection system provides internal connectors between steel piers and precast bent caps. The internal connection is installed in a circular steel pier in the shape of a cross as shown in Figure 1(a). Figure 1(b) shows precast concrete bent cap with an internal connector. After the construction of the steel pier, the precast concrete coping is installed on the pier, as shown in Figure 1(c). When the precast bent cap is installed on the top of a circular steel pier, the internal connection supports the bent cap and can be easily placed. Bent caps, concrete girders, and part of the pier are filled by casting concrete in the field. The internal connection system is installed between a steel pier and precast coping. The upper part of the pier is filled with concrete to integrate the coping. A finishing panel is installed in the pier to control the filling depth of the concrete in the pier. After the insertion of the finishing panel, the pier cap is fixed to the top of the pier and facilitates the placement of the precast coping. The internal connectors are readily installed in the precast concrete bent caps in order to protect the composite behavior with steel piles. The internal connectors of the precast bent caps can improve appearance and eco-friendliness because no separate temporary equipment is used for the installation of the external brackets in the field.

Structurally, the proposed bridge systems minimize the cross section because of continuous sections at the supports of the existing precast concrete bridge. In the case of the simple placement of precast girders on precast bent caps, the structure behaves like simple beams. In simple bridges, a large positive moment is created at the center of the span, which increases the cross-section of the girder and thus involves higher construction and maintenance costs. The 


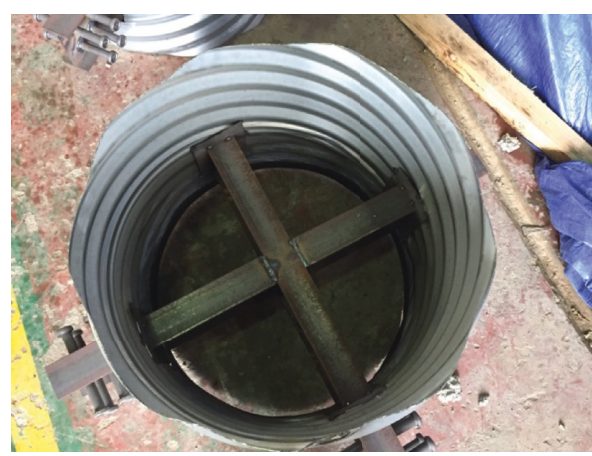

(a)

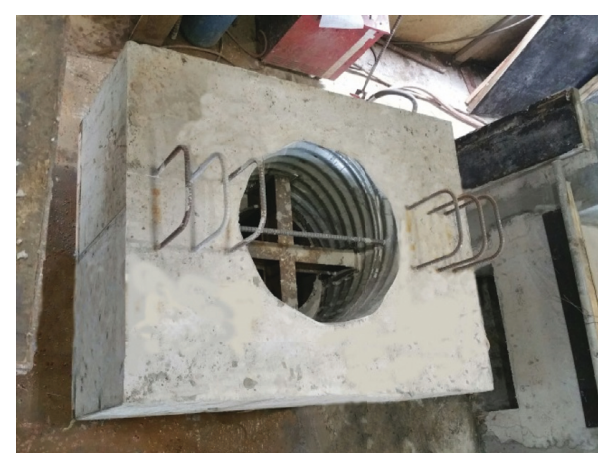

(b)

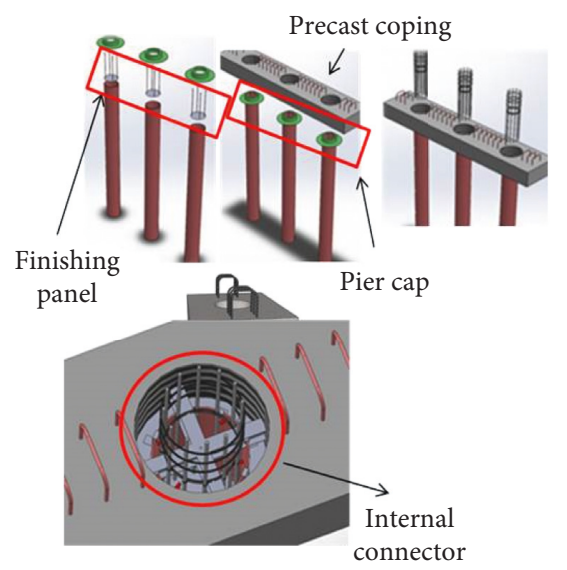

(c)

Figure 1: Precast concrete bent cap with internal connector. (a) Internal connector, (b) precast concrete bent cap, and (c) construction stages.

proposed bridge forms a frame-type structure by placing precast girders and casting concrete for continuous connection. The behavior of the bridge changes from that of simple beams to that of a continuous beam, which generates a negative moment at the support and reduces the section forces of the precast girders. Decreasing the section forces of a bridge reduces the cross section of the girders, which lowers the construction cost and improves the appearance significantly.

\section{Experimental Program}

In this study, a full-scale connection specimen with a $10.0 \mathrm{~m}$ span was fabricated to analyze the composite behavior of the connection part. The structural performance of the proposed systems was analyzed by performing a negative moment performance test. Figure 2 shows the geometry of the test unit. Figure 2(a) shows the floor plan. The specimen was fabricated with a $10.0 \mathrm{~m}$ total length and a $1.5 \mathrm{~m}$ width to allow flexural behavior. The length of the precast girder was $4.7 \mathrm{~m}$ each. The height of the precast bent cap was designed to be $0.6 \mathrm{~m}$, considering the structural stability of the girder, and the height of the steel pile was $0.5 \mathrm{~m}$. The schematic of the longitudinal section is shown in Figure 2(b). The proposed system minimizes field processes by incorporating precast members. This construction step shows only one segment; the actual structure is completed by connecting such segments laterally. The proposed bridge is simple to construct. This is because the cross section of the center span of the bridge is T-shaped and the cross section of the bridge portion is rectangular. There is no need to construct separate decks because slabs were included in the precast girder of the proposed structure. Moreover, it is possible to reduce marine environment pollution because cast-in-place concrete is only needed at the connection section.

Figure 2(c) displays the cross-sectional view of the central section, and Figure 2(d) presents the detailed cast-in-place section view. The placement of reinforcing bars and the fastening positions of the field assembly couplers are shown in Figure 2(d). The field assembly couplers were fastened on both sides to minimize construction errors, and the fastening position was determined to be $0.75 \mathrm{~m}$ from the center of the specimen. The internal connector was installed at a depth of $150.0 \mathrm{~mm}$ in the bent cap. The bent cap and part of the pier were filled with concrete and integrated with the cast-in-place section during production. The diameter of the round steel pipe was $508 \mathrm{~mm}$ and the reinforcing bar was D29. The tensile strength of steel coupons was fabricated with five coupons, and the compressive strength of concrete specimens was fabricated with three specimens. The yield strength of steel was tested by ASTM E8 to obtain $235 \mathrm{MPa}$ [25]. The compressive strength of concrete was $34.6 \mathrm{MPa}$ according to ASTM C39 [26]. 


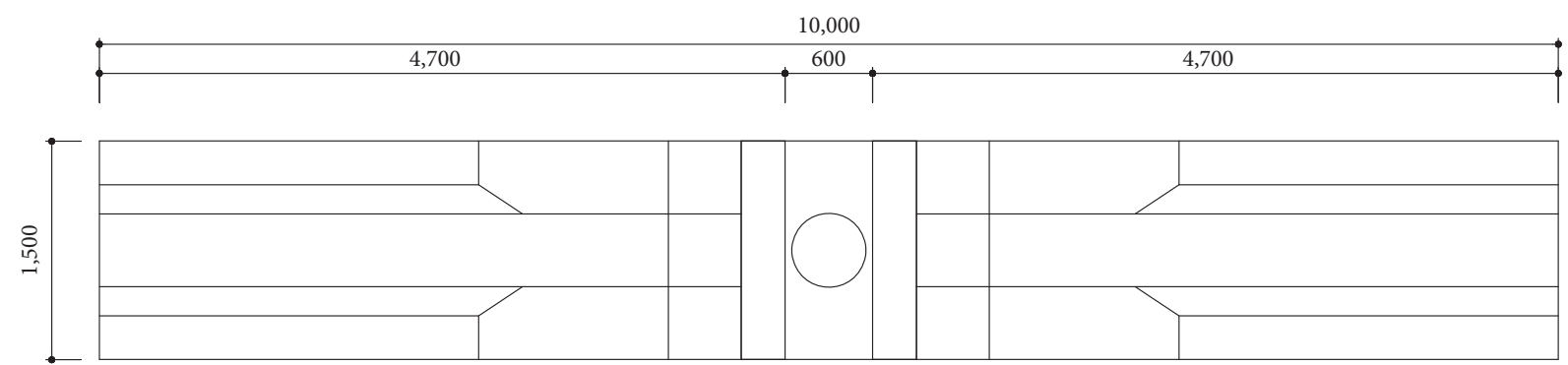

(a)

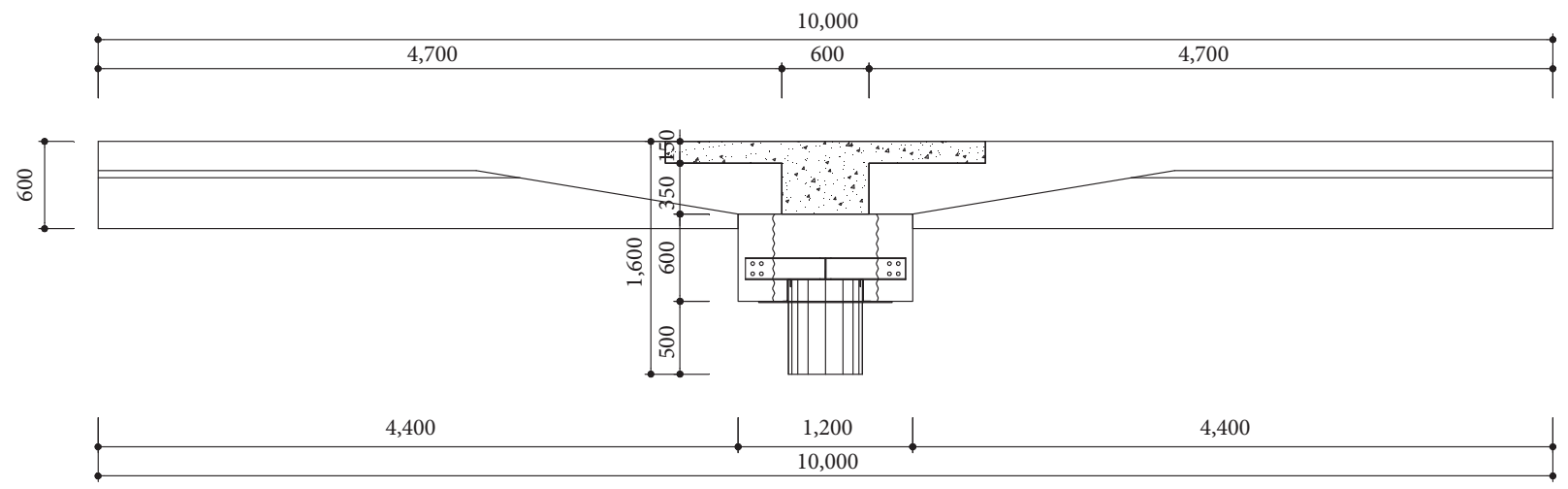

(b)

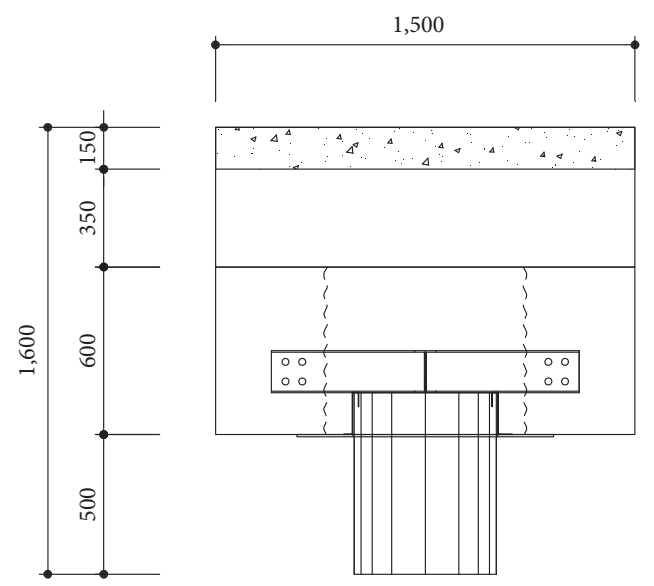

(c)

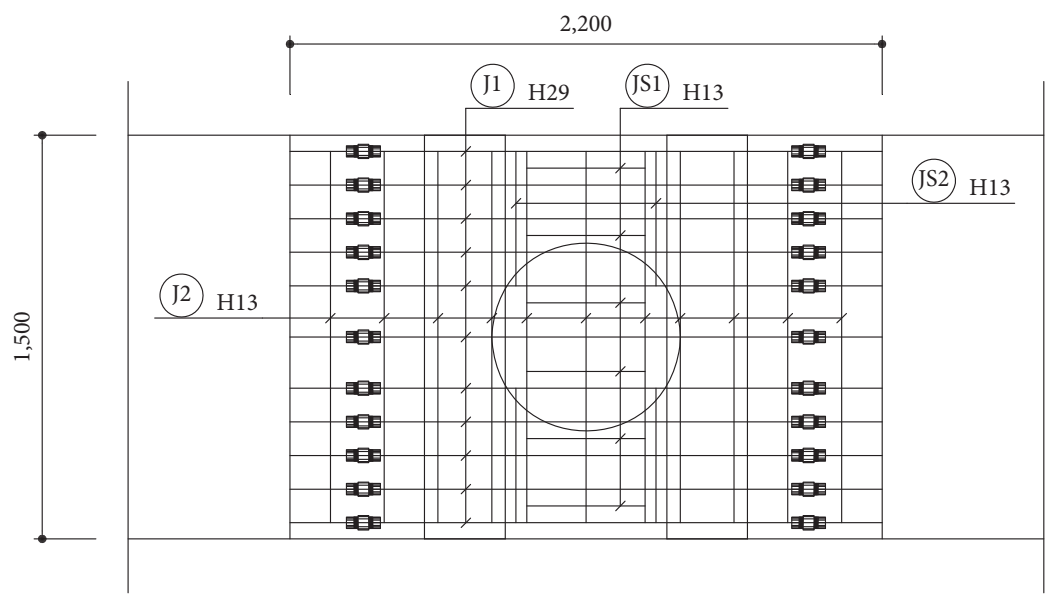

(d)

Figure 2: Geometry of test unit. (a) Floor plan, (b) longitudinal section, (c) cross-sectional view, and (d) cast-in-place section view. 
The specimen fabrication procedures are shown in Figure 3. In this study, the full-scale specimen was turned upside down. A full-scale test unit is heavy, so there is a problem in setting up the test specimens after completing the test specimens. Therefore, the upside-down specimen was fabricated, and a three-point static loading test was performed. As shown in Figure 3(a), the precast girders and bent cap were factorymade. The precast bent cap with the internal connector was fabricated, as shown in Figure 3(b). At this time, steel strain gauges were installed on the reinforcing bars embedded in the precast girders and precast bent cap. Figure 3(c) shows the fabricated steel pile with a bracket installed. After curing the precast girders, the field assembly couplers between the girders were fastened, as shown in Figure 3(d). The precast concrete bent cap and steel pier were placed on the connected precast girders, as shown in Figure 3(e). Figure 3(f) shows the concrete cast into the steel pile to fill the cast-in-place section, the bent cap, and the inside of the pile. When casting concrete in the connection part, one side of the formwork was made of acrylic to confirm that the cast-in-place section was filled with concrete without any voids.

Figure 4 displays the installed specimen. In the case of the normal direction, two actuators are required. However, it is not possible to use two actuators at the same time without error. Therefore, as mentioned earlier, upside-down specimens were prepared, and the three-point static loading test was performed. Figure 4(a) illustrates the displacement transducer and strain gauges installed on the specimen. The displacement transducer was installed at the center of the specimen to measure the deflection of the specimen due to an increase in load. A $200 \mathrm{~mm}$ displacement transducer was used, and the strain gauges were installed on the concrete and the reinforcing bars of cross-sections. The crack gauges were set up at the joint of the cast-in-place section and the girders to examine the point of crack formation and the number of cracks. Figure 4(b) shows the installation of the specimen. Actuators with a $2,000 \mathrm{kN}$ capacity were used for loading. The test was performed at a $0.02 \mathrm{~mm} / \mathrm{s}$ loading rate using the displacement control method. The supports of the specimen were set to a $7.0 \mathrm{~m}$ span, and enough overhead clearance was obtained for displacement measurements. The supports were installed at the actual loading positions. The supports were installed at the actual loading positions. The design load was converted to the load obtained by subtracting the moment owing to the weight from the normal bending moment [27]. The design load moment $(M)$ is calculated as shown in equation (1). $\varnothing M_{\mathrm{n}}$ is the nominal moment and $M_{\mathrm{d}}$ is the self-weigh moment. The concentrated load used in the experiment was calculated by dividing the design load moment by the length, as given in equation (2). The calculation results indicated that the cross-section of the specimen reached the design strength when the load was $448.0 \mathrm{kN}$ in the test.

$$
\begin{aligned}
M & =\varnothing M_{\mathrm{n}}-M_{\mathrm{d}}, \\
P & =\frac{4 M}{L} .
\end{aligned}
$$

The cracking moment $\left(M_{\mathrm{cr}}\right)$ was calculated as in equation (3). This experiment was set up in the upside-down direction and the self-weight moment was excluded from the cracking moment, as given in equation (4). The crack load is then determined based on the cracking moment in test $\left(M_{\mathrm{crt}}\right)$ as shown in equation (5).

$$
\begin{aligned}
M_{\mathrm{cr}} & =\frac{f_{\mathrm{r}} \cdot I_{\mathrm{g}}}{y_{\mathrm{t}}}, \\
M_{\mathrm{crt}} & =M_{\mathrm{cr}}-M_{\mathrm{d}}, \\
P_{\mathrm{cr}} & =\frac{4 M_{\mathrm{crt}}}{L},
\end{aligned}
$$

where $I_{\mathrm{g}}$ is the cross-sectional secondary moment, $y_{\mathrm{t}}$ is the distance from the center of the shape to the tension side, and $f_{\mathrm{r}}$ is the modulus of rupture in crack.

\section{Finite Element Analysis}

In this study, finite element (FE) analysis was performed to verify the performance results of the connection where the negative moment occurs. ABAQUS was used for the FE analysis [28]. The dimensions of the FE model were the same as those of the specimen. That is, the total length was $10.0 \mathrm{~m}$ and the supports were simply supported at a $7.0 \mathrm{~m}$ apart. 3D solid elements (C3D8R) were used for concrete members and steel piers. The couplers and the reinforcing bars were also modeled as solid elements placed in the same positions as in the test specimen. The connection system is modeled individually as solid elements. In the case of the coupler and internal connector, it is assumed that it is perfect bond composites, and the node is shared with the concrete member. In addition, the cross-shaped inner support device and steel cap were combined with a steel pier using composite function (merge) within the ABAQUS program. After completing the individual part modeling, the element mesh is generated to minimize the error of each node. The results of the material test were used for the material properties of the concrete. The FE analysis considered the nonlinearity of the materials using plasticity for the reinforcing bars. Tables 1 and 2 present compressive properties and tensile properties of the concrete material, respectively. The proposed FE model used a concrete damaged plasticity model by ABAQUS programs to define the plasticity fields for the tensile and compressive behavior of the concrete [29-32]. The concrete damaged plasticity FE model supplies a wide-ranging capability for concrete cracking modeling and other quasibrittle materials. It uses theories of isotropic damaged elasticity in combination with isotropic tensile and compressive plasticity to characterize the inelastic behavior of concrete. Material model in this study involves with the combination of nonassociated multihardening plasticity and isotropic damaged elasticity to define the irreparable damage that occurs during the fracturing process. The elasticity modulus of the concrete was $27537 \mathrm{MPa}$ and Poisson's ratio of the concrete was 0.18 . The modulus of elasticity and Poisson's ratio of the steel material were $200,000 \mathrm{MPa}$ and 0.3 , respectively. Figure 5(a) displays the FE model by member. Figure 5(b) shows the joint 


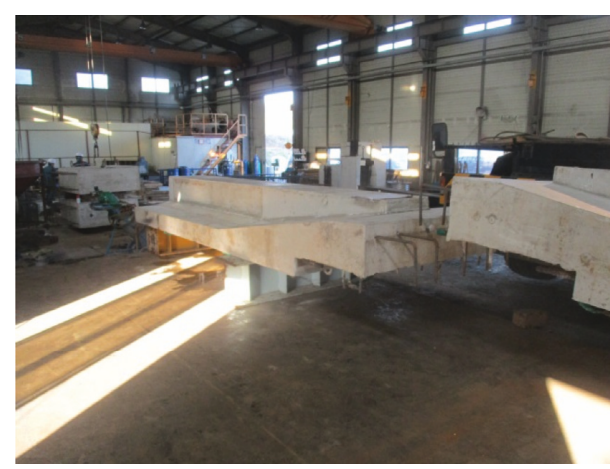

(a)

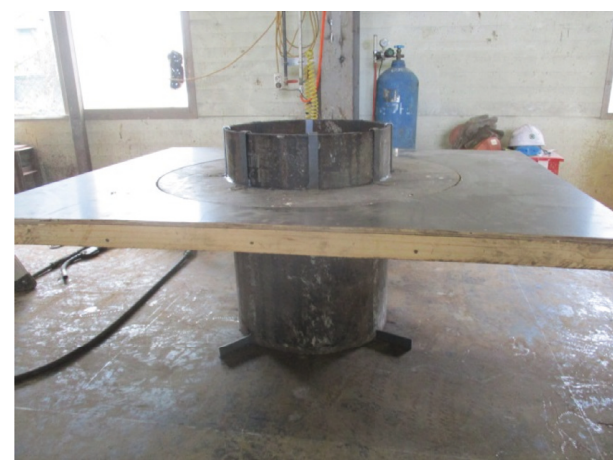

(c)

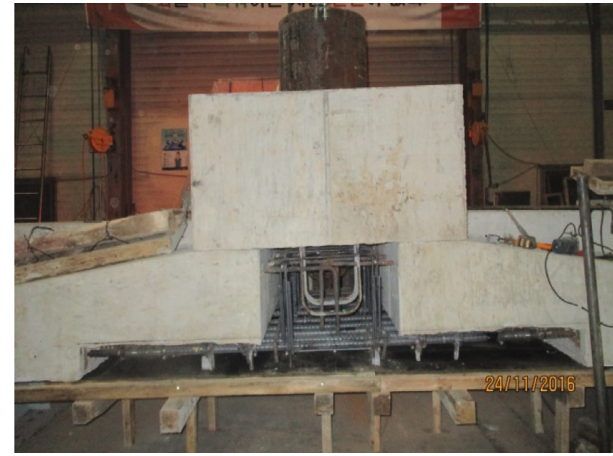

(e)

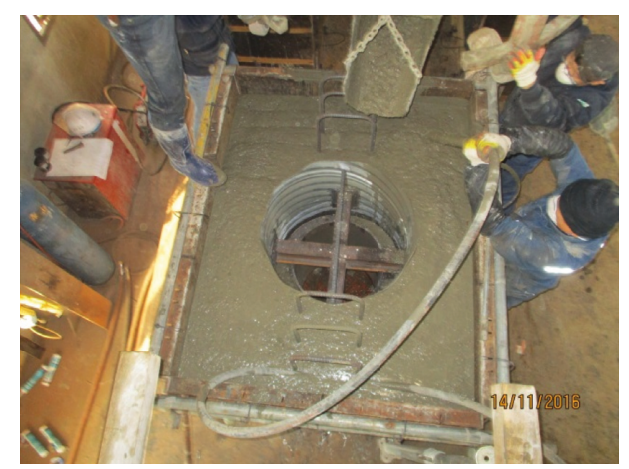

(b)

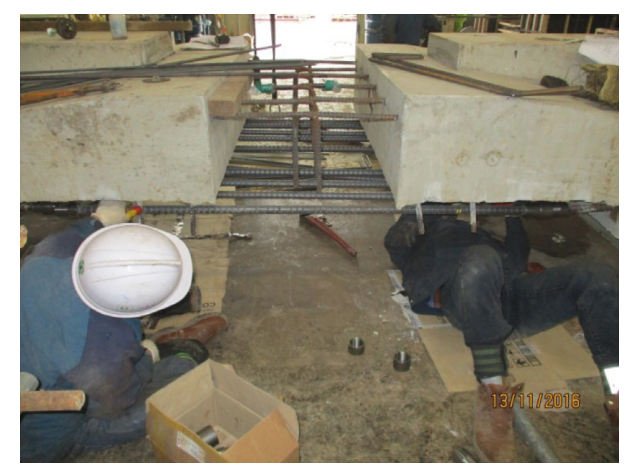

(d)

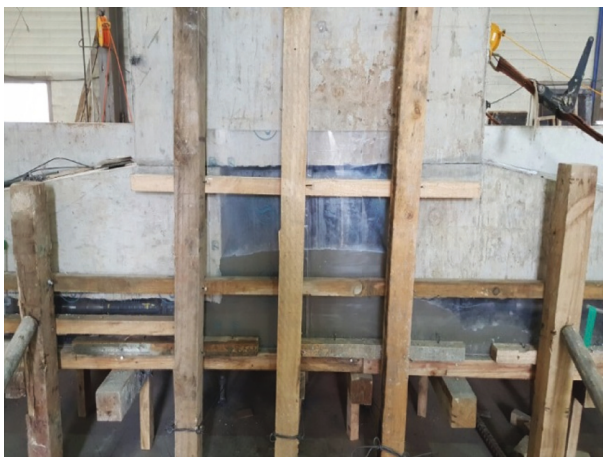

(f)

Figure 3: Fabrication procedures. (a) Fabrication of precast girders, (b) fabrication of precast bent cap, (c) fabrication of steel pier, (d) fastening the couplers, (e) placement of precast bent cap on girders, and (f) curing of concrete.

setup of the FE model. In this study, the girders and the cast-inplace part were divided in the FE model because the cracks in the joints were predicted as shown in Figure 5(b). After this disconnection, the upper girder connection part was connected using rigid links and both the lower girder and the cast-in-place part were connected using spring elements. The stiffness values of the spring elements were set with reference to a previous study of the concrete crack interface modeling [33-36]. Figure 5(c) presents the loading position and boundary conditions.

\section{Experimental and Numerical Results}

The displacement results analyzed the center of the specimen. A FE analysis model for the same size as the test specimen was used in this study for comparison with the experimental results at each loading step. Figure 6 compares the load-displacement results at the center of the analysis model with the experimental results. In the experimental results, nonlinear behavior associated with the initial crack in the concrete occurred at the joint of the cast-in-place part and the precast girder when about $130.0 \mathrm{kN}$ was loaded. FE analysis showed that the displacement increased more steeply after approximately $178.0 \mathrm{kN}$ as the cracks propagated. As the cracks in the concrete at the joints occurred, the tensile stresses mainly occurred in the reinforcing bars. The specimen failed at roughly $711.0 \mathrm{kN}$, and a displacement of approximately $70.0 \mathrm{~mm}$ occurred. Experimental results indicate that all members were safe up to approximately $155 \%$ of the design load. This tendency is due to the fact that the internal connector in the coping, the bent caps, and the girders have an appropriate composite behavior in the 


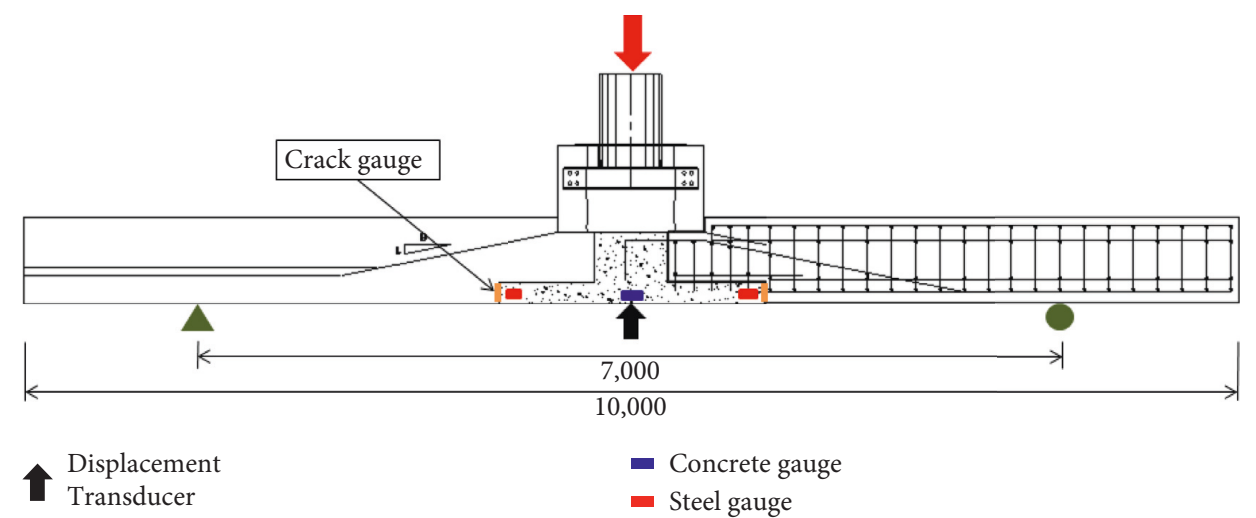

(a)

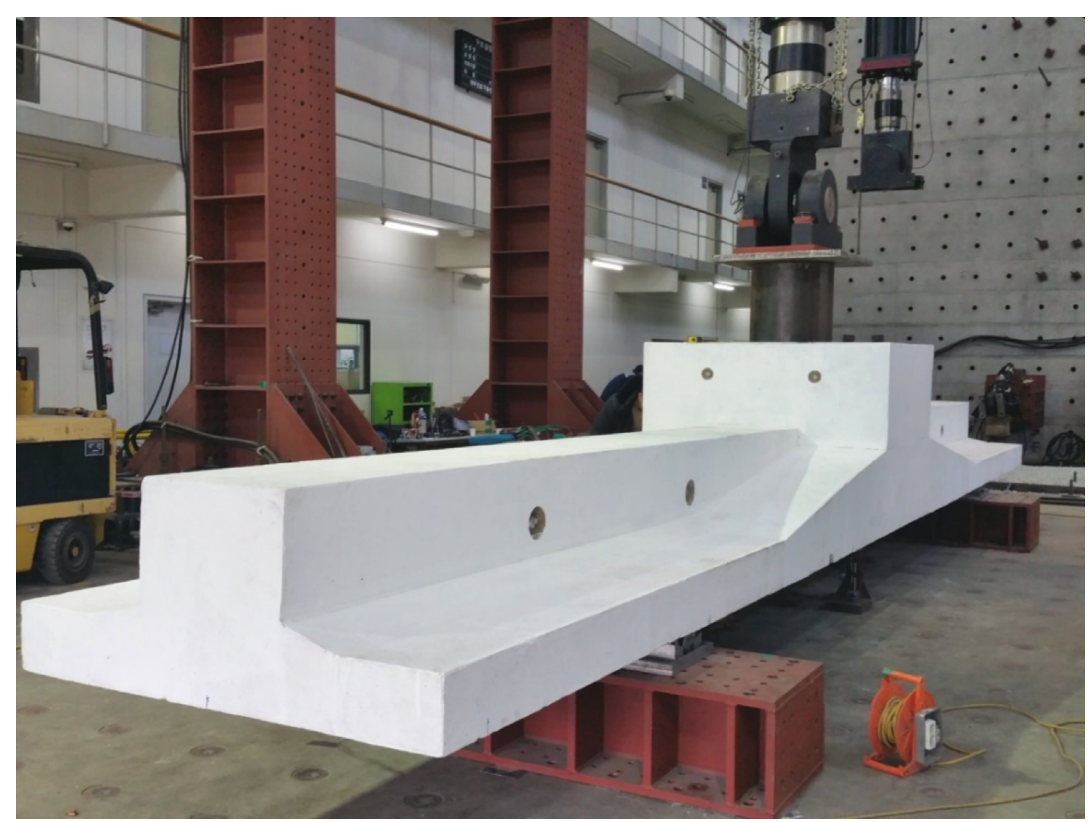

(b)

Figure 4: Layout of test setup. (a) Sensor layout and (b) test setup.

TABLE 1: Compressive properties of concrete materials.

\begin{tabular}{lccc}
\hline \multicolumn{2}{c}{ Compression hardening } & \multicolumn{2}{c}{ Compression damage } \\
Stress (MPa) & Inelastic strain & Damage $C$ & Inelastic strain \\
\hline 9 & 0 & 0 & 0 \\
12.11868 & $4.48 e-5$ & 0 & $4.48 e-5$ \\
18.0037 & $5.93 e-5$ & 0 & $5.93 e-5$ \\
24.18227 & $9.25 e-5$ & 0 & $9.25 e-5$ \\
30.00462 & 0.00046 & 0 & 0.00046 \\
24.14165 & 0.00154 & 0.1172412 & 0.00153 \\
12.14165 & 0.00341 & 0.3578292 & 0.00342 \\
3.154534 & 0.00704 & 0.536919 & 0.00704 \\
\hline
\end{tabular}

negative moment connection part. The FE analysis results indicated that nonlinear behavior occurred at approximately $133.0 \mathrm{kN}$ due to cracks in the concrete. The maximum load of the $\mathrm{FE}$ analysis model was roughly $752.0 \mathrm{kN}$, indicating a $5.7 \%$ error relative to the test results. It is also concluded that the proposed FE analysis predicted the behavior of the negative moment part similar to that of the test results. The
TABle 2: Tensile properties of concrete materials.

\begin{tabular}{lccc}
\hline \multicolumn{2}{c}{ Tension stiffening } & \multicolumn{2}{c}{ Tension damage } \\
Stress $(\mathrm{MPa})$ & Inelastic strain & Damage $T$ & Inelastic strain \\
\hline 1.199358 & 0 & 0 & 0 \\
1.7052 & $1.99 e-5$ & 0 & $1.99 e-5$ \\
1.121886 & $9.62 e-5$ & 0.24384 & $9.62 e-5$ \\
0.5176338 & 0.00017 & 0.41783 & 0.00017 \\
0.1357524 & 0.00041 & 0.55223 & 0.00041 \\
0.0339456 & 0.00065 & 0.58806 & 0.00065 \\
\hline
\end{tabular}

load-strain results of the reinforcing bars in the FE analysis model are compared with the experimental results in Figure 7. Initially, the strain of the reinforcing bars increased linearly, but nonlinear behavior resulted from the formed concrete cracks at the joint. The reinforcing bars yielded at the maximum load of the specimen, and it is concluded that the final failure mode of the specimen was yielding of the reinforcing bars at the joint. It was also concluded that the 


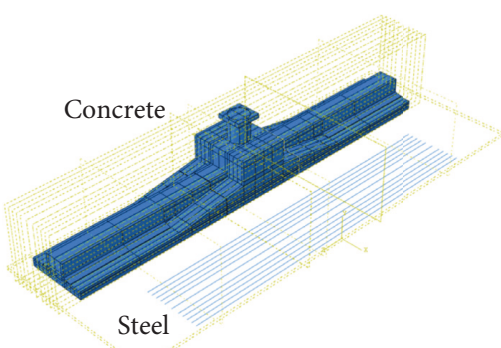

(a)

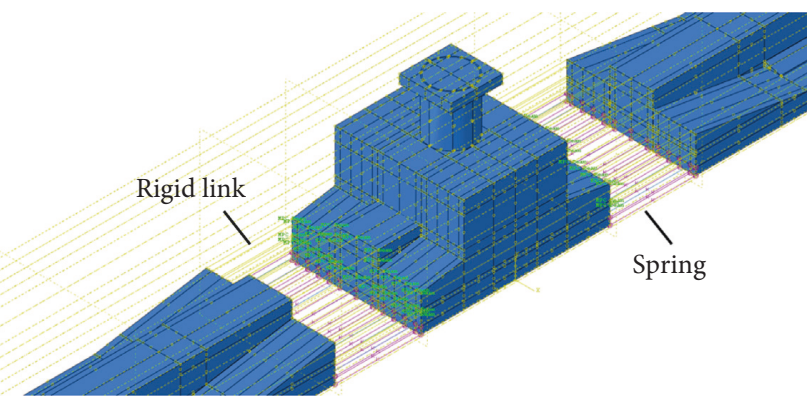

(b)

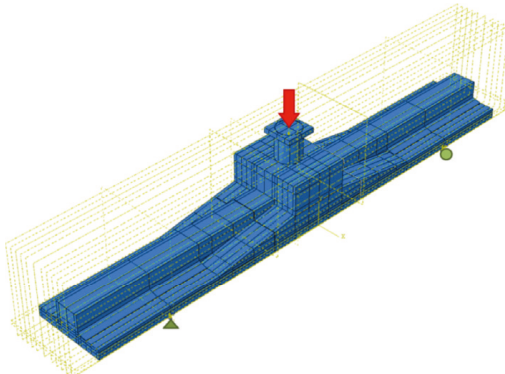

(c)

Figure 5: Finite element analysis. (a) Part modeling, (b) joint setup of analysis model, and (c) boundary condition.

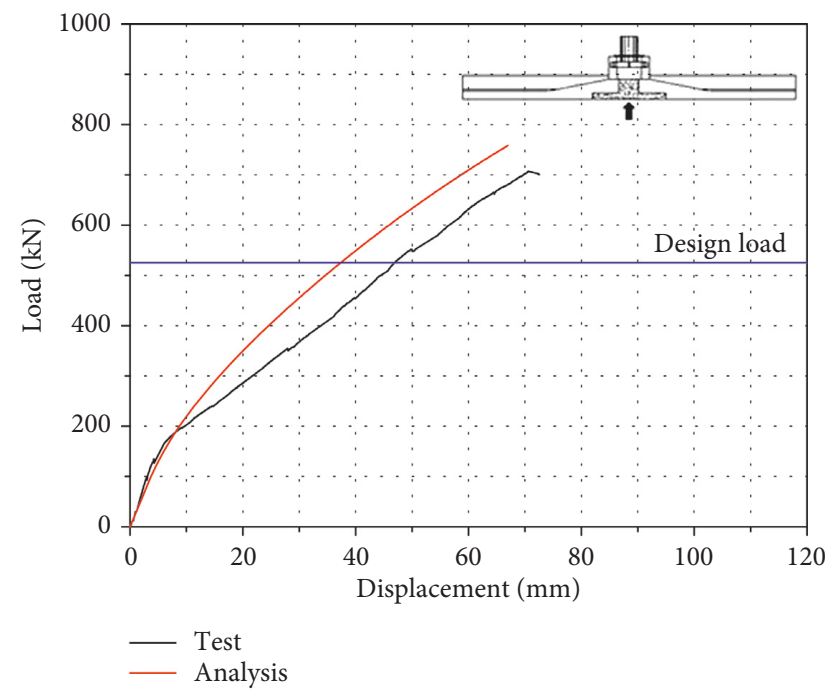

FIGURE 6: Load-displacement relationship at center.

couplers did not fail when the maximum load was applied. The trend of the FE analysis results was similar to that of the experimental results, but the initial strain was higher than that of the test results. It is concluded that large deformation of the reinforcing bars occurred from the beginning because the joint was connected with springs. It was confirmed that the overall behavior of the FE model proposed in this study due to the negative moment is similar to that presented by the test results.

Figure 8 shows the load-strain relationship in the concrete at the center. The concrete strain increased as the tensile stress increased in the lower part of the specimen up to approximately $133.0 \mathrm{kN}$. As cracks formed in the concrete,

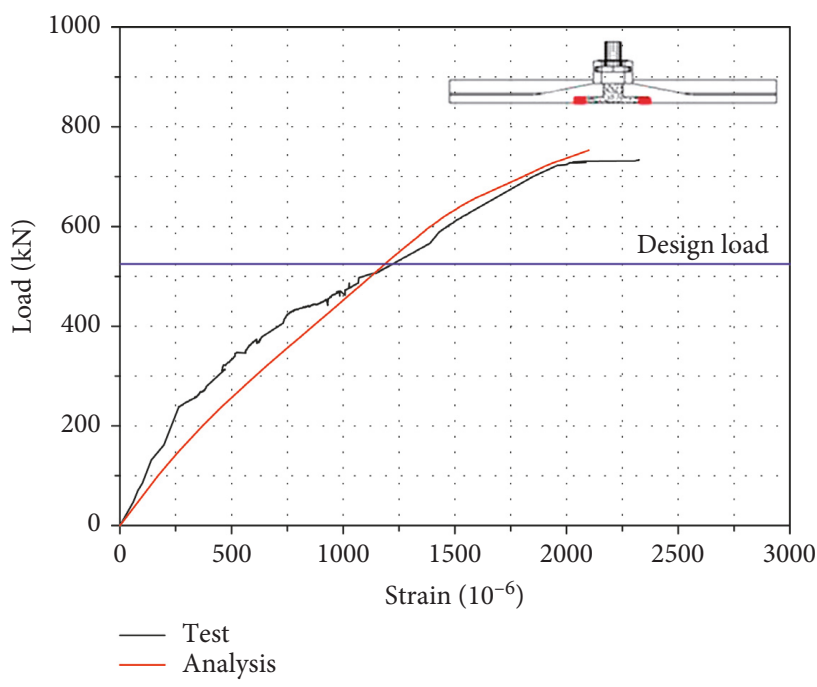

FIGURE 7: Load-strain relationship of the reinforcing bars at joint.

nonlinear behavior occurred. At stresses greater than $165.0 \mathrm{kN}$, the strain decreased. This is because the concrete could no longer withstand tensile stresses due to cracking. The loadcrack displacement results at the joint between the cast-in-place part and the precast girder are shown in Figure 9. In this study, the expected crack initiation load was predicted to be approximately $65.0 \mathrm{kN}$, based on equation (5). At approximately $130.0 \mathrm{kN}$ load, cracks formed and the cracks increased linearly. The final crack width was estimated to be approximately $2.9 \mathrm{~mm}$. It is concluded that the precast concrete connection and the concrete connection at the site have an appropriate composite behavior owing to the crack load being higher than $65 \mathrm{kN}$, which is the calculated crack load in the design. 


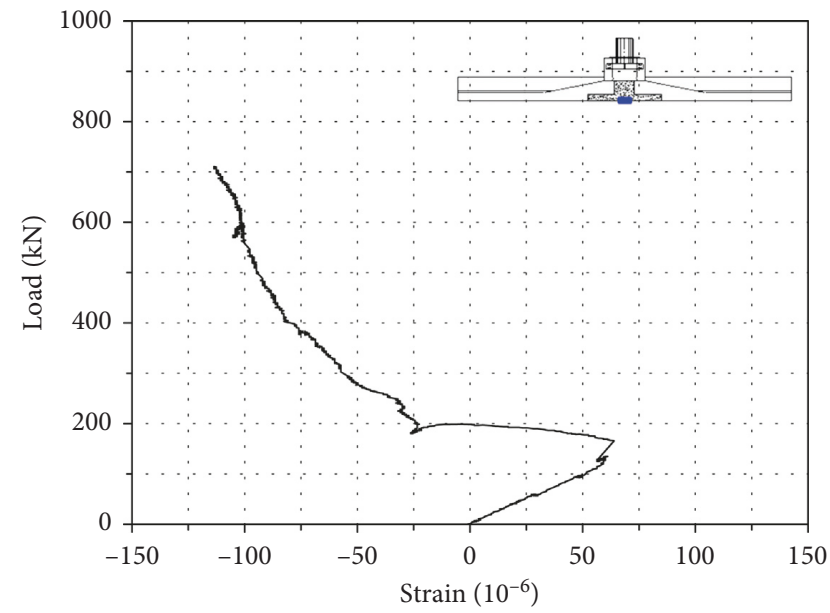

Figure 8: Load-strain relationship of the concrete at center.

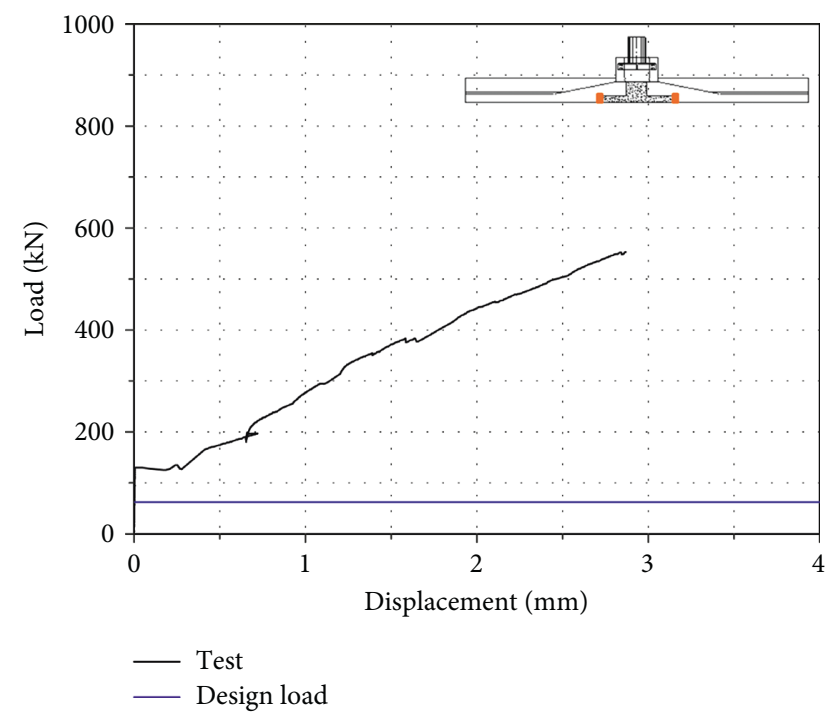

FIGURE 9: Load-crack displacement relationship at joint.

In this study, a FE model was used to study the tensile stress in concrete, the existence of cracks was examined, and the results were compared with the crack pattern of the specimen. Table 3 illustrates the stress distribution in the FE model for each loading step. High initial tensile stress occurred at the lower part of the joint between the girder and the cast-in-place part. As the load increased, stress was concentrated intensively toward the center at the bottom of the FE model. The stress distribution was concentrated at the location between the joint and the center of the specimen when the maximum load was applied. Table 3 presents the crack pattern predicted based on the stress distribution in the FE model. The initial crack occurred at the joint of the girder and the cast-in-place part, and cracks expanded toward the upper part of the center as the load increased. Cracks occurred throughout the lower part, and cracks were mostly distributed at the joints and the center when the maximum load was applied. The cracks formed at the center have similar shapes to those in the cast-in-place part.
Figure 10 illustrates the crack pattern of the test specimen. Figure 10(a) displays a schematic presentation of the crack pattern under the maximum load, while Figure 10(b) shows the final cracks present in the specimen. Cracks mostly occurred in a shape similar to that of the cast-in-place part. This is because the cracks were mainly present in the discontinuous surfaces of the concrete. Additionally, flexural cracks caused by the principal tensile stress occurred in the lower part of the specimen. FE analysis shows that the development of the flexural cracks was due to the composite behavior of the specimen even though cracks primarily emerged at the joints. It is concluded that the proposed finite element model can accurately predict the discontinuity of the concrete connection when the nonlinear spring element is used.

\section{Conclusion}

In this study, a full-scale specimen of the connection of a bridge with a $10.0 \mathrm{~m}$ span was fabricated and its structural behavior was analyzed by conducting a performance test of the connection for negative moment. Moreover, the behavior of each loading step was compared and analyzed using a finite element model. The following conclusions can be drawn:

(1) In this test, the maximum load of the test specimen was evaluated to be approximately $711.0 \mathrm{kN}$, which was $155 \%$ of the design load. The final failure mode was the reinforcing bars yielding at the joints. It was concluded that the internal connection part did not fail when the maximum load was applied. It is also concluded that the proposed bridge ensures the proper composite behavior of internal connection device, bent cap, and girder in the bent cap. The composite behavior of the proposed bridge reduces the cross section of the girder, which reduces the construction cost and greatly improves the appearance.

(2) The first crack that was physically observed occurred at the joint of the girder and the cast-in-place part under a load of about $130.0 \mathrm{kN}$. It is concluded that the precast concrete connection and the concrete connection at the site have a sufficient composite behavior due to the crack load higher than $65 \mathrm{kN}$, which is the calculated crack load in the design. Cracks gradually grew in a shape similar to that of the cast-in-place part, and typical flexural cracks occurred in the entire lower part.

(3) The FE analysis results showed an error of approximately $5.7 \%$ when referenced to the measured value in terms of strength. Also, the proposed FE model is similar to the nonlinear behavior of reinforcing bars. The proposed FE analysis predicted the behavior of the negative moment part similar to that of the test results.

(4) The crack pattern of the analysis model was predicted. In this analysis model, tensile stress was mainly distributed at the joints of the girder, in the cast-in-place part, and in the lower portion. Cracks were observed 
TABLE 3: Stress distribution and crack pattern from FE model.

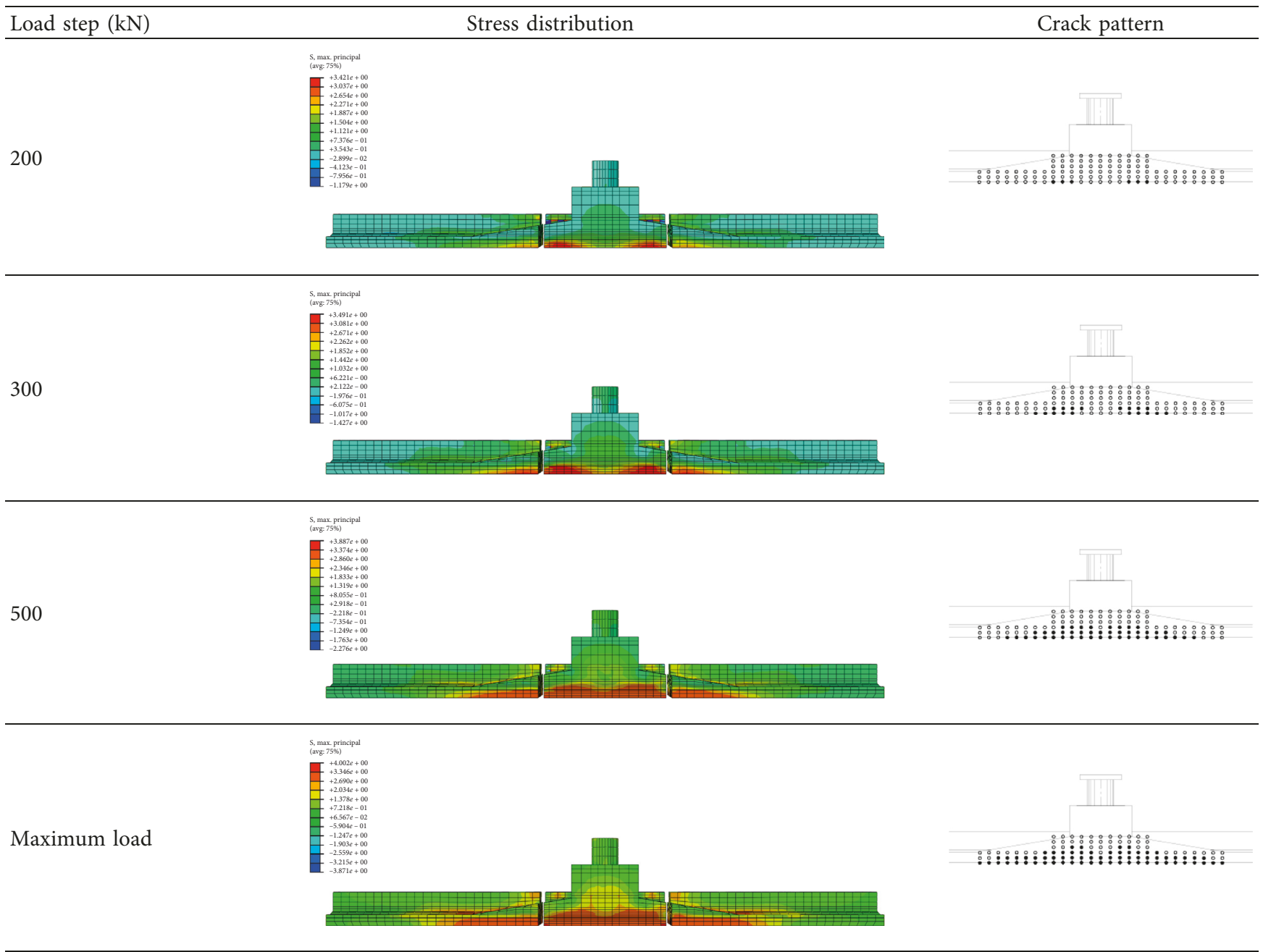

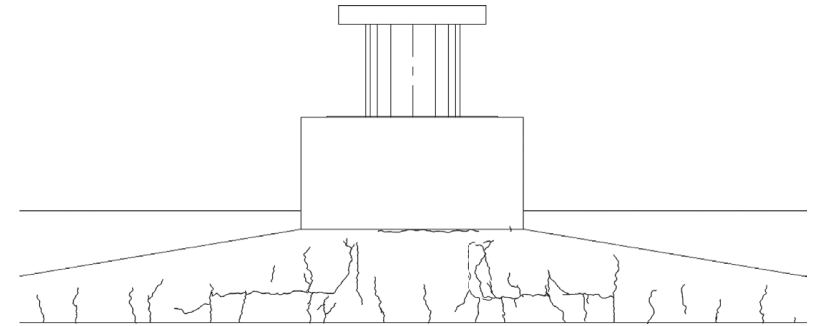

(a)

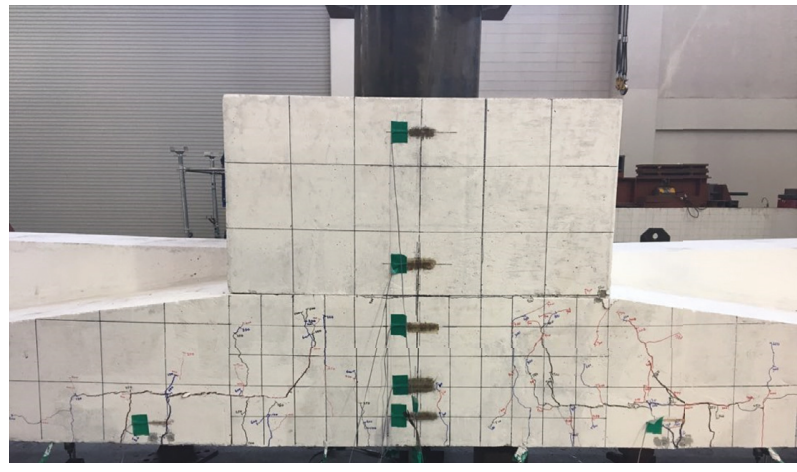

(b)

Figure 10: Crack pattern of the specimen. (a) Crack pattern under the maximum load and (b) final cracks.

at the joints and throughout the lower part, and the proposed finite element model can predict the discontinuity of the concrete connection similar to the actual behavior by using the nonlinear spring element.

\section{Data Availability}

The data used to support the findings of this study are included within the article. 


\section{Additional Points}

(i) Construction of conventional concrete marine structures on site is difficult and can cause environmental pollution. (ii) A new bridge system is proposed to minimize the amount of construction on site using precast structures. (iii) A full-scale connection specimen with a $10.0 \mathrm{~m}$ span is fabricated and tested to investigate the composite behavior of the negative moment region. (iv) A finite element model was also developed and verified against experimental results. (v) The proposed bridge ensures the composite behavior and has $155 \%$ higher capacity than the designed load at the negative moment connection region.

\section{Conflicts of Interest}

The authors declare that they have no conflicts of interest.

\section{Acknowledgments}

This study is a basic research project conducted with support from the National Research Foundation of Korea through government funds (Ministry of Science, ICT and Future Planning, South Korea). The project numbers are 2017R1A2B4010467 and 2017R1C1B1006732.

\section{Supplementary Materials}

Construction of conventional concrete marine structures on site is difficult and can cause environmental pollution. A new bridge system is proposed to minimize the amount of construction on-site using precast structures. A full-scale connection specimen with a $10.0 \mathrm{~m}$ span is fabricated and tested to investigate the composite behavior of the negative moment region. A finite element model was also developed and verified against experimental results. The proposed bridge ensures the composite behavior and has 155\% higher capacity than the designed load at the negative moment connection region. (Supplementary Materials)

\section{References}

[1] S. D. Cramer, B. S. Covino Jr., S. J. Bullard et al., "Corrosion prevention and remediation strategies for reinforced concrete coastal bridges," Cement and Concrete Composites, vol. 24, no. 1, pp. 101-117, 2002.

[2] M. G. Stewart and D. V. Rosowsky, "Time-dependent reliability of deteriorating reinforced concrete bridge decks," Structural Safety, vol. 20, no. 1, pp. 91-109, 1998.

[3] J. E. Padgett, A. Spiller, and C. Arnold, Statistical Analysis of Coastal Bridge Vulnerability Based on Empirical Evidence from Hurricane Katrina, CRC Press, Boca Raton, FL, USA, 2012.

[4] K. A. T. Vu and M. G. Stewart, "Structural reliability of concrete bridges including improved chloride-induced corrosion models," Structural Safety, vol. 22, no. 4, pp. 313-333, 2000.

[5] C. Perea, J. Alcala, V. Yepes, F. Gonzalez-Vidosa, and A. Hospitaler, "Design of reinforced concrete bridge frames by heuristic optimization," Advances in Engineering Software, vol. 39, no. 8, pp. 676-688, 2008.
[6] C. H. E. N. Zhaoyuan, "Durability design of concrete structures," Architecture Technology, vol. 5, 2003.

[7] C. Andrade, J. L. Sagrera, and M. A. Sanjuán, "Several years study on chloride ion penetration into concrete exposed to Atlantic Ocean water," in Proceedings of the RILEM Proc. 19: 2nd International Rilem Workshop on Testing and Modeling the Chloride Ingress into Concrete, C. Andrade and J. Kropp, Eds., vol. 19, pp. 121-134, pp. 121-134, RILEM Publications SARL, Cachan, France, 2000.

[8] P. K. Mehta, Concrete in the Marine Environment, CRC Press, Boca Raton, FL, USA, 2002.

[9] M. B. Anoop and K. Balaji Rao, "Application of fuzzy sets for remaining life assessment of corrosion affected reinforced concrete bridge girders," Journal of Performance of Constructed Facilities, vol. 21, no. 2, pp. 166-171, 2007.

[10] J. R. Zhang and L. Wang, "Estimated approach to carrying capacity of existing reinforced concrete bridge member," China Journal of Highway and Transport, vol. 2, p. 8, 2006.

[11] C. G. Soares, Y. Garbatov, A. Zayed, and G. Wang, "Influence of environmental factors on corrosion of ship structures in marine atmosphere," Corrosion Science, vol. 51, no. 9, pp. 2014-2026, 2009.

[12] Z. Zhang, X. Yao, and H. Zhu, "Potential application of geopolymers as protection coatings for marine concreteII. Microstructure and anticorrosion mechanism," Applied Clay Science, vol. 49, no. 1-2, pp. 7-12, 2010.

[13] J. D. Garcia-Espinel, D. Castro-Fresno, P. Parbole Gayo, and F. Ballester-Muñoz, "Effects of sea water environment on glass fiber reinforced plastic materials used for marine civil engineering constructions," Materials \& Design, vol. 66, pp. 46-50, 2015.

[14] C. Bradner, T. Schumacher, D. Cox, and C. Higgins, "Experimental setup for a large-scale bridge superstructure model subjected to waves," Journal of Waterway, Port, Coastal, and Ocean Engineering, vol. 137, no. 1, pp. 3-11, 2010.

[15] A. Caner and P. Zia, "Behavior and design of link slabs for jointless bridge decks," PCI Journal, vol. 43, no. 3, pp. 68-80, 1998.

[16] A. de la Fuente, A. Aguado, C. Molins, and J. Armengou, "Numerical model for the analysis up to failure of precast concrete sections," Computers \& Structures, vol. 106-107, pp. 105-114, 2012.

[17] K. Baskar, N. E. Shanmugam, and V. Thevendran, "Finiteelement analysis of steel-concrete composite plate girder," Journal of Structural Engineering, vol. 128, no. 9, pp. 1158$1168,2002$.

[18] M. A. Issa and H. A. Abdalla, "Structural behavior of single key joints in precast concrete segmental bridges," Journal of Bridge Engineering, vol. 12, no. 3, pp. 315-324, 2007.

[19] H. Lee, D. Cho, Z. An, and W. Chung, "Composite behavior of steel I-girders connected to inverted-T bent cap," International Journal of Steel Structures, vol. 14, no. 4, pp. 711-721, 2014.

[20] Z. G. Ko, H. Lee, W. Bin, Z. An, and W. Chung, "An experimental study on joint performance of steel I-girders connected to inverted-T bent cap in fatigue testing," KSCE Journal of Civil Engineering, vol. 21, no. 7, pp. 2828-2836, 2014.

[21] A. R. Marí and M. Valdés, "Long-term behavior of continuous precast concrete girder bridge model," Journal of Bridge Engineering, vol. 5, no. 1, pp. 22-30, 2000.

[22] B. N. Shah, K. Sennah, M. R. Kianoush, S. Tu, and C. Lam, "Experimental study on prefabricated concrete bridge girder- 
to-girder intermittent bolted connections system," Journal of Bridge Engineering, vol. 12, no. 5, pp. 570-584, 2007.

[23] Ministry of Oceans and Fisheries, Harbor and Fishery Design Criteria, Ministry of Oceans and Fisheries, Sejong, Korea, 2014.

[24] B. Huh, C. Lam, and B. Tharmabala, "Effect of shear stud clusters in composite girder bridge design," Canadian Journal of Civil Engineering, vol. 42, no. 4, pp. 259-272, 2015.

[25] ASTM, E8, "Standard test methods for tension testing of metallic materials," in Annual Book of ASTM Standards, vol. 3, pp. 57-72, ASTM International, West Conshohocken, PA, USA, 2004.

[26] ASTM, C39, Standard Test Method for Compressive Strength of Cylindrical Concrete Specimens, ASTM International, West Conshohocken, PA, USA, 2005.

[27] Civil, MIDAS, Integrated Solution System for Bridge and Civil Structures, MIDAS Information Technology Co., Ltd., Seoul, Korea, 2009.

[28] ABAQUS, ABAQUS/Standard User's Manual-Version 6.71, ABAQUS, Inc., Pawtucket, RI, USA, 2007.

[29] T. Jankowiak and T. Lodygowski, "Identification of parameters of concrete damage plasticity constitutive model," Foundations of Civil and Environmental Engineering, vol. 6, no. 1, pp. 53-69, 2005.

[30] H. Lee, W. T. Jung, and W. Chung, "Post-tension near-surface mounted strengthening system for reinforced concrete beams with changes in concrete condition," Composites Part B: Engineering, vol. 161, pp. 514-529, 2019.

[31] H. Lee, W. T. Jung, and W. Chung, "Post-tension nearsurface-mounted strengthening systems of full-scale PSC girders," Construction and Building Materials, vol. 151, pp. 71-82, 2017.

[32] H. Y. Lee, W. T. Jung, and W. Chung, "Flexural strengthening of reinforced concrete beams with pre-stressed near surface mounted CFRP systems," Composite Structures, vol. 163, pp. 1-12, 2017.

[33] D. Asahina, E. N. Landis, and J. E. Bolander, "Modeling of phase interfaces during pre-critical crack growth in concrete," Cement and Concrete Composites, vol. 33, no. 9, pp. 966-977, 2011.

[34] J. Xiao, W. Li, D. J. Corr, and S. P. Shah, "Effects of interfacial transition zones on the stress-strain behavior of modeled recycled aggregate concrete," Cement and Concrete Research, vol. 52, pp. 82-99, 2013.

[35] C. Amadio, C. Bedon, M. Fasan, and M. R. Pecce, "Refined numerical modelling for the structural assessment of steelconcrete composite beam-to-column joints under seismic loads," Engineering Structures, vol. 138, pp. 394-409, 2017.

[36] A. Prakash, N. Anandavalli, C. K. Madheswaran, J. Rajasankar, and N. Lakshmanan, "Three dimensional FE model of stud connected steel-concrete composite girders subjected to monotonic loading," International Journal of Mechanics and Applications, vol. 1, no. 1, pp. 1-11, 2011. 


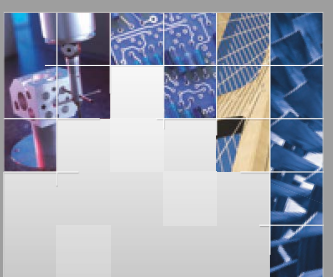

\section{Enfincering}
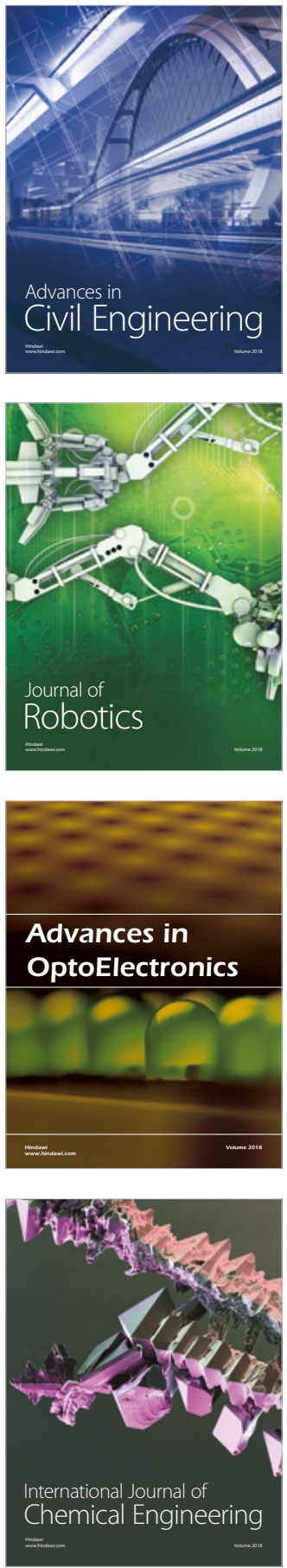

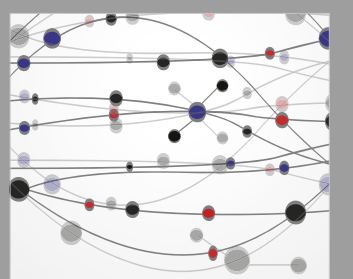

\section{Rotating \\ Machinery}

The Scientific World Journal

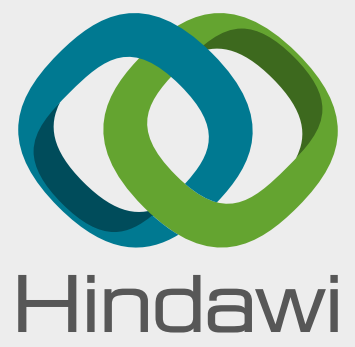

Submit your manuscripts at

www.hindawi.com
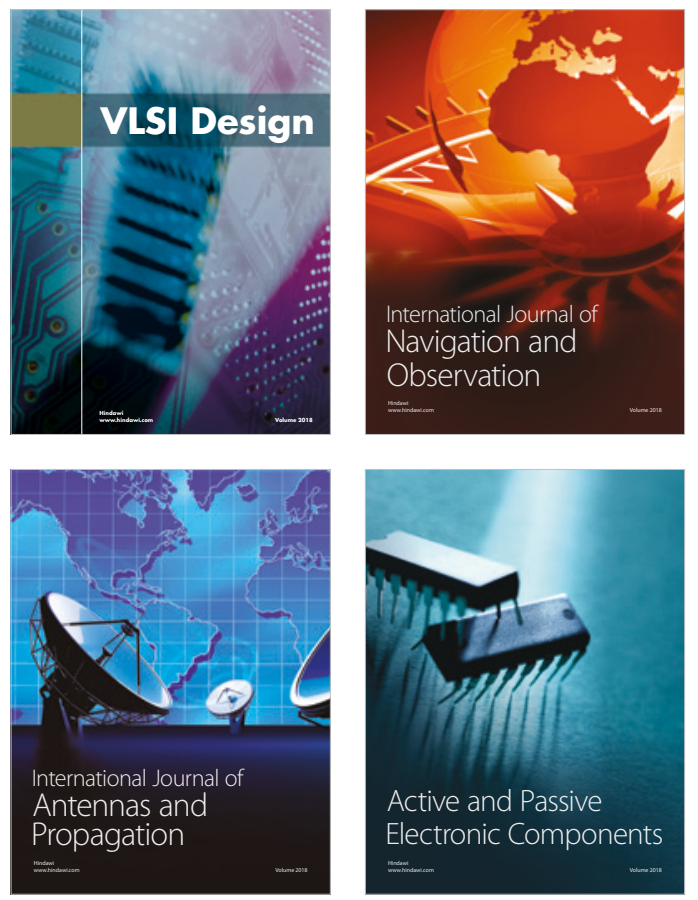
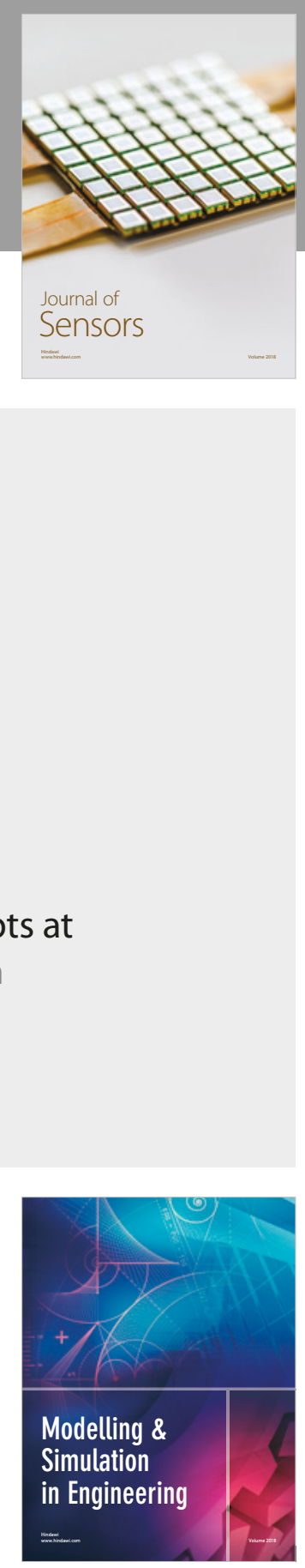

\section{Advances \\ Multimedia}
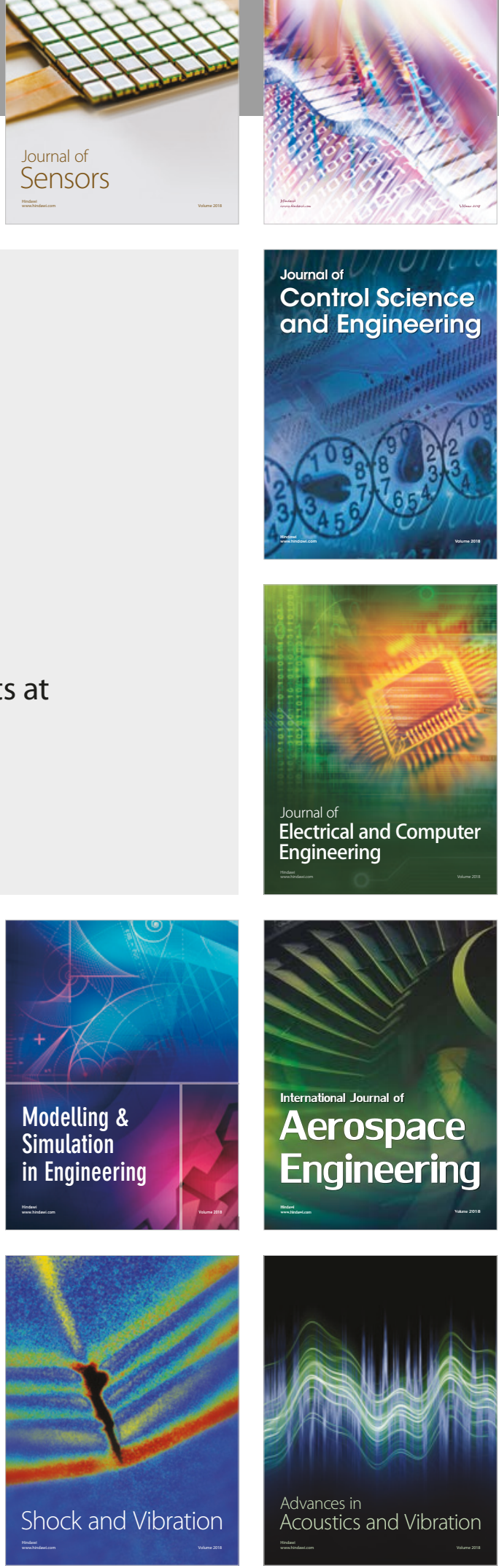